\title{
Effects of Cigarette Smoking on Hematological Parameters and von Willebrand Factor Functional Activity Levels in Asymptomatic Male and Female Arab Smokers
}

\author{
Anwar M. Al-Awadhia Suad M. AlFadhlia Nada Y. Mustafa ${ }^{a}$ Prem N. Sharma ${ }^{b}$ \\ a Department of Medical Laboratory Sciences, Faculty of Allied Health Sciences, and b Health Sciences Computer \\ Center, Kuwait University, Kuwait
}

\section{Key Words}

Smoking $\cdot$ Gender $\cdot$ von Willebrand factor $\cdot$ Enzyme-linked immunoassay

\begin{abstract}
Objectives: This study aimed at determining the effects of cigarette smoking based on gender, on several hematological parameters and von Willebrand factor protein in the asymptomatic Arab population of Kuwait. Subjects and Methods: Ninety-two subjects participated in this study: 55 males (31 smokers and 24 nonsmokers) and 37 females (18 smokers and 19 nonsmokers). Complete blood count results were obtained using Beckman Coulter Hematology Analyzer. Von Willebrand factor functional activity was determined using an enzyme-linked immunoassay-based test in which anti-von Willebrand factor IgG monoclonal antibody was used that recognizes a functional epitope of the protein. The coagulation profile was obtained using $\mathrm{ACL}^{\circledR} 9000$ coagulation analyzer. Results: Male smokers had significantly higher levels of white blood cell count $(p=0.03)$ and von Willebrand factor protein levels $(p=0.029)$, and a significantly shorter thrombin time ( $p=0.019)$ than nonsmokers. Smoking did not appear to affect any of the parameters analyzed in females as no significant difference was found between smokers and nonsmokers $(p>0.05)$. Conclusion: Our results
\end{abstract}

showed that smoking affected white blood cell count and von Willebrand factor levels in males and not in females, and as such could be potential markers for smoking-induced endothelial damage in asymptomatic Arab male smokers.

Copyright $\odot 2008$ S. Karger AG, Basel

\section{Introduction}

A strong correlation has been found between cigarette smoking and atherosclerosis and cardiovascular disease $[1,2]$. Several studies have considered endothelial injury to be a key initiating event in the pathogenesis of cardiovascular disorders [3-5]. However, the precise pathophysiology of the adverse effects of smoking on endothelium is not very clear. Potential mechanisms for smokinginduced damage include increased platelet reactivity and aggregability [6], change in lipids and lipoprotein levels $[7,8]$, alteration in hemostasis system [9], and increased counts and activation of neutrophils $[10,11]$.

Smoking has also been shown to influence levels of von Willebrand factor protein (vWF). vWF, synthesized and stored in endothelial cells and megakaryocytes, has been reported to be a useful marker for endothelial cell damage [11-13]. This protein, which acts as a carrier and stabilizer for factor VIII, was reported to facilitate platelet

\section{KARGER}

Fax +4161306 1234

E-Mail karger@karger.ch

www.karger.com
(C) 2008 S. Karger AG, Basel

1011-7571/08/0172-0149\$24.50/0

Accessible online at:

www.karger.com/mpp
Dr. Anwar Al-Awadhi

Department of Medical Laboratory Sciences

Faculty of Allied Health Sciences, Kuwait University, PO Box 31470 90805 Sulaibekhat (Kuwait)

Tel. +965 498 3592, Fax +965 498 3835, E-Mail alawadhi@hsc.edu.kw 
aggregation and adhesion to the subendothelium of an injured vessel wall [12].

As smoking has been reported to cause morphological and biochemical disturbances to the endothelium [5], this effect is associated with increased levels of vWF due to endothelial injury by smoke components including nicotine, carbon monoxide and free radicals $[10,14,15]$. However, there are conflicting reports regarding the effects of smoking on vWF levels in the two sexes [16], and amongst smokers of different consumption levels [17]. Also, very few published studies have examined vWF in the Arab population [18] and, to our knowledge, none in Arab female smokers.

In this study, a comparative analysis was done between smokers and nonsmokers of both sexes in the Arab population of Kuwait. We investigated the effects of smoking on white blood cell (WBC) counts, platelet counts, prothrombin time, activated partial thromboplastin time, thrombin time and vWF levels.

\section{Materials and Methods}

\section{Subjects, Blood Counts and Coagulation Analysis}

The subjects included 55 males ( 31 smokers and 24 nonsmokers) and 37 females (18 smokers and 19 nonsmokers). Average age and range for male smokers and nonsmokers were 36.5 (20-75) years and 26 (19-57) years, respectively. Those of female smokers and nonsmokers were 38.5 (23-64) years and 22 (19-57) years, respectively. Cigarette consumption was classified according to the criteria of Rastogi et al. [19]: mild, 1-10 cigarettes/day; moderate, 11-20 cigarettes/day; heavy consumption, $>20$ cigarettes/day. The subgroup of male smokers consisted of 8 mild smokers, 14 moderate smokers and 9 heavy smokers, whereas in the female subgroup there were 9 mild smokers, 7 moderate smokers and 2 heavy smokers. Informed consent was obtained from the subjects.

Two tubes of venous blood were collected early in the morning from each subject in a fasting state of at least $12 \mathrm{~h}$. K3-EDTA (15\%) Becton Dickinson vacuum collection tubes were used for complete blood count determination and sodium citrate (3.8\%) Becton Dickinson vacuum collection tubes for the analysis of coagulation profiles and vWF. Complete blood count was determined using GenS ${ }^{\mathrm{TM}}$ Haematology Analyzer (Beckman Coulter Co., USA). The coagulation profile for 60 subjects, including prothrombin time, activated partial thromboplastin time and thrombin time, was obtained using ACL ${ }^{\circledR} 9000$ Coagulation Analyzer (Beckman Coulter Co., USA).

Determination of $v W F$ Functional Activity Levels

Within $2 \mathrm{~h}$ of blood collection, plasma was separated by centrifugation at $1,500 \mathrm{~g}$ for $15 \mathrm{~min}$. vWF levels were measured using enzyme-linked immunoassay (Shields Diagnostics Ltd., Dundee, UK). The assay utilizes a monoclonal antibody RFF-VIII:R/1 that specifically recognizes the GP1ba binding domain on vWF (an epitope that reflects vWF function [20]). The assay was performed in duplicate for each sample according to the manufacturer's directions. In brief, plasma was added to wells of microtiter plates coated with a preparation of purified murine anti-vWF IgG monoclonal antibody. After 1-hour incubation, successive washes were done and a secondary antibody (a conjugate of horseradishperoxidase-labeled mouse anti-human monoclonal anti-vWF conjugate) was added. After a final wash, the specifically bound antibody was traced by the addition of a substrate solution. The optical density at $450 \mathrm{~nm}$ was determined using a microwell reader system (Organon Teknika, The Netherlands). Test samples were compared with a calibration curve prepared using reference plasma calibrated against the 4 th international standard for factor VIII and vWF in plasma (code: 97/586).

\section{Statistical Analysis}

Data were analyzed using the statistical package for social sciences (SPSS, PC version 14.0; SPSS Inc., Chicago, Ill., USA). The quantitative variables were examined for normality with Kolmogorov-Smirnov test. The descriptive statistics are presented as medians with interquartile and range. Any association between gender and smoking status was ascertained with $\chi^{2}$-test. Hematological values between smokers and nonsmokers were compared using nonparametric Mann-Whitney test. A general linear model univariate procedure was also applied to see any individual or interaction effect of smoking on hematological values in the two sexes. A two-tailed $\mathrm{p}$ value $<0.05$ was considered statistically significant.

\section{Results}

Analysis of hematological findings between smokers and nonsmokers, for males and females, is shown in table 1. A significant increase in the median WBC count $\left(8.5\right.$ vs. $\left.7.1 \times 10^{9} / 1 ; \mathrm{p}=0.03\right)$ and vWF levels (114 vs. 60 $\mathrm{IU} / \mathrm{dl} ; \mathrm{p}=0.029$ ) was observed between male smokers and nonsmokers. Male smokers presented with significantly lower thrombin time values (18.0 s) compared to nonsmokers (19.5 s; $p=0.019)$. No statistically significant difference was observed between female smokers and nonsmoker in any of the parameters analyzed ( $p>0.05$ ). Also, there was no statistically significant association between cigarette consumption rate in both sexes and the hematological parameters studied ( $p>0.05)$.

Despite significant differences in age between smokers and nonsmokers in both sexes $(\mathrm{p}=0.019$ for male, $\mathrm{p}=0.000$ for female), general linear model univariate analysis showed that age was not a significant contributor to any of the differences seen between the parameters analyzed ( $p>0.05$ ); only smoking had a significant effect on the differences observed in WBC counts and vWF levels $(\mathrm{p}=0.042$ and 0.043 , respectively). This finding was also confirmed using regression analysis (results not shown). 
Table 1. Hematological findings by gender between smokers and nonsmokers

\begin{tabular}{|c|c|c|c|c|c|c|}
\hline Parameter & smokers & nonsmokers & $\mathrm{p}$ value & smokers & nonsmokers & $\mathrm{p}$ value \\
\hline Plt count $\left(150-400 \times 10^{9} / 1\right)$ & $243(91-324)$ & $248(172-364)$ & 0.285 & $262(167-417)$ & $275(157-366)$ & 0.796 \\
\hline \multicolumn{7}{|l|}{ vWF functional activity levels } \\
\hline$(50-180 \mathrm{IU} / \mathrm{dl})^{1}$ & $114(10-256)$ & $60(18-145)$ & $0.029^{*}$ & $110(14-214)$ & $100(14-238)$ & 0.543 \\
\hline TT (15-19s) & $18(16.5-22)$ & $19.5(17.5-20.1)$ & $0.019^{*}$ & $17.1(16.5-23.5)$ & $18.9(16-19.8)$ & 0.171 \\
\hline
\end{tabular}

Plt $=$ Platelet PT $=$ prothrombin time; APTT = activated partial thromboplastin time; $\mathrm{TT}=$ thrombin time. $\mathrm{p}$ value representing significant difference: ${ }^{*} \mathrm{p}<0.05$.

${ }^{1}$ Eighty percent of subjects fall within the normal range. The percentage of subjects $<50$ and $>80$ IU/dl correlates with the percentage reported by the manufacturer for asymptomatic subjects.

\section{Discussion}

Although strong epidemiological evidence links smoking to cardiovascular disease, the exact mechanisms of this link remain poorly understood. Some of the adverse effects of smoking include: initiation of endothelial injury [3-5], acceleration of coronary progression and new lesion formation [21], and overall alterations in lipid and hemostatic systems [7-10]. Detecting endothelial damage may be the most useful step in the early diagnosis of atherosclerosis. Although the endothelium releases many molecules into the circulation and arterial wall, not all of them are specific to the endothelium and are therefore of limited research or diagnostic potential [11]. vWF is perhaps the most useful marker for endothelial damage as it is specific to endothelial cells, stable and may be relevant to the disease process [11].

$\mathrm{WBC}$ count is another inexpensive and simple marker. In this study, the high WBC count in male smokers is consistent with other published reports [10,22-24]. While leukocytosis may simply be a marker of smoking-induced tissue damage, the high count can promote cardiovascular diseases through multiple pathologic mechanisms that mediate inflammation, plug the microvasculature, induce hypercoagulability and promote infarct expansion $[25,26]$. In fact several studies have shown that WBC count is an independent predictor of atherosclerosis and cardiovascular disease $[25,26]$. The high WBC count in our male smoking subjects may suggest that they might be at greater risk for developing cardiovascular diseases than nonsmokers.

Smoking and vWF in Arab Smokers
Another inflammatory marker (fibrinogen) was also reported to be elevated in smokers compared to nonsmokers in several published studies [24, 27, 28]. Although fibrinogen levels were not measured in our subjects, the short thrombin time value (the time required for thrombin to convert fibrinogen to an insoluble fibrin clot) reported in our study is a strong indicator of elevated levels of fibrinogen in smokers. This test has been reported to be directly affected by abnormal/high levels of fibrinogen $[29,30]$. The higher levels of fibrinogen in male smokers may promote cardiovascular disease by affecting blood viscosity, platelet aggregation and general fibrin formation [24]. This finding was not seen in female smokers in our study (as previously reported [27]).

The vWF was significantly higher in male smokers compared to nonsmokers $(\mathrm{p}=0.029)$ as previously reported [17]. Measuring vWF using an assay that measures functional activity of the protein was reported to correlate strongly with vWF antigen levels in normal subjects $(r=0.90)$, and to differentiate between functionally active vWF from degraded antigen [31]. The high levels observed in male subjects imply injury to the endothelium. Although the mechanism by which smoking influences the release of vWF remains unclear, it has been proposed that this increase may be due to cytotoxic effects of lipid peroxidase formed by oxygen free radicals, and the effects of nicotine and carbon monoxide among others [10, $14,15]$.

Smoking did not appear to affect any of the parameters analyzed in female smokers $(p>0.05)$. This finding is not consistent with previously published work regard- 
ing the adverse effects of smoking in females, where smoking was reported to increase WBC count [22], and vWF levels in female subjects [16] as reported in Western, non-Arab populations. The reason for the lack of an effect in our sample population is unclear, but may be related to low cigarette consumption rate in female compared to male subjects. Fifty percent of female smokers in our study were classified as mild smokers $(<10$ cigarettes/ day), compared to $25 \%$ of male smokers. A positive correlation between adverse effects of smoking and daily usage of cigarettes has been reported $[3,16]$, with males displaying earlier and more intensive use of cigarettes [2].

The small number of female smokers in this study may also contribute to the lack of effect observed here. It is worth mentioning that it was extremely difficult to recruit female smokers in this study as social constraints in Middle Eastern societies make it difficult for women to openly discuss their smoking behavior.

There is some controversy in the literature regarding gender differences and the effects of smoking. Prisco et al. [16] reported that smoking increased vWF in both sexes. Kumari et al. [17], on the other hand, reported an increase in vWF levels in male smokers but a lack of such an effect in females as in our study. The differences in findings may be explained by diverse ethnic composition and the amount of cigarettes smoked in these studies.

It has been reported that there is a strong association between race and vWF $[18,32]$; therefore, the influence of racial origin should always be considered in the laboratory evaluation of vWF. Although the effects of smoking on vWF had been investigated previously $[9,10,16,17]$, the contribution of our work lies in the ethnicity of the subject group as studies focusing on Arab subjects are limited. Results of this work will allow better understanding of smoking-related hematological alterations in this part of the world.

\section{Conclusion}

Our results showed that cigarette smoking affected WBC counts and vWF levels in male but not in female subjects and as such could be potential markers for smoking-induced endothelial damage in asymptomatic Arab male smokers.

\section{Acknowledgment}

This work was funded by Kuwait University through the Research Administration (Research Initiation Grant No. ZN 04/04). The authors wish to thank Mrs. Qudsiya Electricwala and Mr. Mehrez Jadaon for excellent technical assistance and Dr. Christopher Dunn for reviewing the manuscript. The authors would also like to acknowledge the Department of Hematology, Mubarak Al-Kabeer Hospital in Kuwait, for the help provided to complete this work.

\section{References}

1 Ross R: The pathogenesis of atherosclerosis: a perspective for the 1990s. Nature 1993;362: 801-809.

2 Doll R, Peto R, Boreham J, Sutherland I: Mortality in relation to smoking: 50 years' observations on male British doctors. $\mathrm{Br}$ Med J 2004;328:1519-1529.

-3 Blann AD, McCollum CN: Adverse influence of cigarette smoking on the endothelium. Thromb Haemost 1993;70:707-711.

4 Blann AD, Lip GY: The endothelium in atherothrombotic disease: assessment of function, mechanisms and clinical implications. Blood Coagul Fibrinolysis 1998;9:297-306.

5 Pittilo RM: Cigarette smoking, endothelial injury and cardiovascular disease. Int J Exp Pathol 2000;81:219-230.

- 6 Fusegawa Y, Goto S, Handa S, Kawada T, Ando Y: Platelet spontaneous aggregation in platelet-rich plasma is increased in habitual smokers. Thromb Res 1999;93:271-278.
7 Halfon ST, Green MS, Heiss G: Smoking status and lipid levels in adults of different ethnic origins: the Jerusalem lipid research clinic program. Int J Epidemiol 1984;13:177183.

8 Cullen P, Schulte H, Assmann G: Smoking, lipoproteins and coronary heart disease risk. Eur Heart J 1998; 19:1632-1641.

-9 Tsiara S, Elisaf M, Mikhailidis DP: Influence of smoking on predictors of vascular disease. Angiology 2003;54:507-530.

10 Blann AD, Kirkpatrick U, Devine C, Naser S, McCollum CN: The influence of acute smoking on leucocytes, platelets and the endothelium. Atherosclerosis 1998;141:133-139.

11 Blann AD, McCollum CN: Von Willebrand factor, endothelial cell damage and atherosclerosis. Eur J Vasc Surg 1994;8:10-15.

12 Blann AD: Is raised von Willebrand factor a marker of endothelial cell damage? Med Hypotheses 1993;41:419-424.
13 Lip GY, Blann A: Von Willebrand factor: a marker of endothelial dysfunction in vascular disorders? Cardiovasc Res 1997;34:255265.

14 Blaes N, Piovella F, Samaden A, BoutherinFalson O, Ricetti M: Nicotine alters fibronectin and factor VIII/vWF in human vascular endothelial cells. Br J Haematol 1986; 64:675-687.

15 Kalra J, Chaudhary AK, Prasad K: Increased production of oxygen free radicals in cigarette smokers. Int J Exp Pathol 1991;72:1-7.

16 Prisco D, Fedi T, Brunelli L, Chiarugi L, Lombardi A, Gianni R, Santoro E, Cappelletti C, Pepe G, Gensini GF, Abbate R: The influence of smoking on von Willebrand factor is already manifesting in healthy adolescent females: the Floren-teen (Florence Teenager) study. Int J Clin Lab Res 1999;29: $150-154$. 
17 Kumari M, Marmot M, Brunner E: Social determinants of von Willebrand factor: the Whitehall II Study. Arterioscler Thromb Vasc Biol 2000;20:1842-1847.

-18 Gader A, Bahakim H, Awadallah S, Malaika S: Ethnic variations in the haemostatic system: comparison between Arabs, Westerners (Europeans and Americans), Asians and Africans. Blood Coagul Fibrinolysis 1995;6: 537-542.

19 Rastogi R, Shrivastava SS, Mehrota TN, Singh VS, Gupta MK: Lipid profile in smokers. J Assoc Physicians India 1989;37:764766.

20 Chand S, McCraw A, Hutton R, Tuddenham EG, Goodall AH: A two-site, monoclonal antibody-based immunoassay for von Willebrand factor: demonstration that vWF function resides in a conformational epitope. Thromb Haemost 1986;55:318-324.

21 Waters D, Lesperance J, Gladstone P, Boccuzzi ST, Cook T, Hudgin R, Krip G, Higginson L: Effects of cigarette smoking on the angiographic evaluation of coronary atherosclerosis: a Canadian Coronary Atherosclerosis Intervention Trial (CCAIT) substudy. Circulation 1996;94:614-621.
22 Smith MR, Kinmonth AL, Luben RN, Bingham S, Day NE, Wareham NJ, Welch A, Khaw KT: Smoking status and differential white cell count in men and women in the EPIC-Norfolk population. Atherosclerosis 2003;169:331-337.

23 Kawada T: Smoking-induced leukocytosis can persist after cessation of smoking. Arch Med Res 2004;35:246-250.

24 Wannamethee SG, Lowe GD, Shaper AG, Rumley A, Lennon L, Whincup PH: Associations between cigarette smoking, pipe/cigar smoking, and smoking cessation, and haemostatic and inflammatory markers for cardiovascular disease. Eur Heart J 2005;26: 1765-1773.

25 Madjid M, Awan I, Willerson JT, Casscells SW: Leukocyte count and coronary heart disease: implications for risk assessment. J Am Coll Cardiol 2004;44:1945-1956.

26 Loimaala A, Rontu R, Vuori I, Mercuri M, Lehtimaki T, Nenonem A, Bond MG: Blood leukocyte count is a risk factor for intimamedia thickening and subclinical carotid atherosclerosis in middle-aged men. Atherosclerosis 2006;188:363-369.

27 Tarallo P, Henny J, Gueguen R, Siest G: Reference limits of plasma fibrinogen. Eur J Clin Chem Clin Biochem 1992;30:745-751.
28 Sinha S, Luben RN, Welch A, Bingham S, Wareham NJ, Day NE, Khaw KT: Fibrinogen and cigarette smoking in men and women in the European Prospective Investigation into Cancer in Norfolk (EPIC-Norfolk) population. Eur J Cardiovasc Prev Rehabil 2005;12: 144-150.

29 Harmening, DM: Clinical Hematology and Fundamentals of Hemostasis. Philadelphia, Davis, 2002, pp 666-667.

30 Kurata M, Sasayaman Y, Yamasaki N, Kitazawa I, Hamada Y, Horri I: Mechanism for shortening PT and APTT in dogs and rats-effects of fibrinogen on PT and APTT. J Toxicol Sci 2003;28:439-443.

-31 Murdock PJ, Woodhams BJ, Mathews KB, Pasi KJ: Von Willebrand factor activity detected in a monoclonal antibody-based ELISA: an alternative to restocetin cofactor platelet agglutination assay for diagnostic use. Thromb Haemost 1997;78:1272-1277.

32 Sukhu K, Poovalingam V, Mahomed R, Giangrande PL: Ethnic variation in von Willebrand factor levels can influence the diagnosis of von Willebrand disease. Clin Lab Haematol 2003;25:247-249. 